\title{
The influence pattern of key factors affecting the purpose of organizational excellence consulting on the efficiency of businesses consulting services (A case study of small and medium-size food enterprises in Tehran province)
}

\author{
Mansour Ezati Jivan
}

MA in Business Administration; Managing Director of Iranian Management System Company (Iran SAMA), Iran

\begin{tabular}{l}
\hline A R T I C L E I N F O \\
\hline Article history: \\
Received July 10, 2011 \\
Received in Revised form \\
October, 3, 2011 \\
Accepted 10 January 2012 \\
Available online \\
16 January 2012 \\
\hline Keywords: \\
Consulting \\
Management consulting \\
Client system \\
Intervention \\
Organizational development (OD) \\
Organization excellence models
\end{tabular}

\section{A B S T R A C T}

Consulting helps managers or other people find appropriate solutions for challenges they face in their businesses. Most of the losses incurred by the people and the society could be prevented using appropriate consultation. Consultation, also, refers to people's participation in decision making. Despite dramatic development in management consulting industry in the world during the last three decades, consulting industry in Iran has faced numerous challenges.

This study aims to examine the factors affecting the efficiency of management consulting services in small and medium-sized businesses and it focuses on food industries in Tehran as a real-world case study. The necessary suggestions regarding the hiring of a consultant and increasing the efficiency of management consulting services in business have been offered in this study. Some recommendations deal with the way that management consultants should respond to the managers' needs, act as a reliable and efficient adviser in public or private businesses and find their position in the Iranian market.

The conceptual model of this study shows the influence of key factors affecting the purpose of consulting on the efficiency of management consulting services. To do the research, 90 people are selected as the sample size in a descriptive study with random sampling of the managers of aforementioned companies using a questionnaire.

Cronbach's alpha method was used to assess the reliability of the questionnaire. For assessing the validity of the questionnaire, we use standard questionnaire, which has already been used.

(C) 2012 Growing Science Ltd. All rights reserved.

\section{Introduction}

In the modern world, there are almost no large organizations or companies not benefiting from the services of consulting companies. The development of management consulting industry depends on the level of organizational maturity. Developed countries have more advanced and profitable management consulting industries. It is clear that in the organizations and institutions, which do not have participatory management, the managers feel that they know everything. Such organizations suffer from old structures based on power relations. Their personnel are neither motivated nor creative, the processes and procedures are quite repetitive and the methods and tools used in such organizations belong to the past. There is no dynamic and positive interaction in these organizations

\footnotetext{
* Corresponding author. Tel: +989126980426

E-mail addresses: m.ezzati@gmail.com (M. Ezzati) 
and they do not care for management consulting. It seems, at the first glance, that the weaker organizations need management consulting more than others; but in the real world it is not true. Those who are wiser refer to the management consultants more than the others. Here, begins another part of the struggle for survival.

\subsection{Statement of the Problem}

Consulting is performed by putting experiences together over the time and is not transmitted by techniques such as training. In training-based approaches, models and their applications are discussed theoretically, but in consulting, each model should be adapted to the conditions of the organization and the country and should turn into a practical program. All these stages need expertise and hard work; however, in order for the efficiency of consulting to develop, competitive conditions are needed. Since management consulting needs ingenuity and creativity for applying the theories, examining the situation of consulting and the factors affecting its efficiency in Iranian businesses is highly important.

Among the problems of the management consulting industry are the lack of certain criteria for consultants' work, lack of adequate understanding of the necessity and importance of consultants' role, lack of tendency towards and acceptance of change in different levels of organizations and unclear borders between consulting and performance.

\subsection{Significance of the Study}

Management consulting industry has turned into one of the lucrative fields in the service markets of the world in the 21st century (Graubner, 2006). Porter believes that organizations unable to rethink, review and reconstruct are dead and this indicates the necessity of management consulting. With regard to the extent and variety of units and expertise, the managers, alone, are no longer able to be fully informed of all issues associated with the organizations and to make decisions effectively and reasonably. The managers' power is reduced increasingly due to the complexity of the environment. In other words, a specialized duty is assigned to each unit and because of the limited expertise, time and increasing administrative duties, the managers cannot completely control all the units. Therefore, the senior manager is just one of the decision makers, not the only one. Therefore, the more technocrats are gaining power day by day, the more senior managers are losing their power. In fact, the main purpose of management consulting is to assist the managers and staff to develop their abilities in an environment full of self-confidence, understanding and organizational efficiency. In fact, as the consultant's expertise and experience increase, the selection and design of appropriate programs become easier.

Research regarding the management consulting is very low and insignificant among the Iranian sources. There are only a few number of studies on the factors affecting the performance improvement of consulting services in small and medium-sized businesses.

\subsection{Purpose of the study}

It is evident that food industries in Iran are amongst the leading and modernized industries of the country due to the increasing demands and needs. Along with the importance and prosperity, proper management of organizational processes plays a key role in encountering and managing this great demand and importance. Improper management of these processes may result in unacceptable outcomes. The main purpose of this study is to identify the managers' need for consulting and to determine its limitations. The scientific objective is to review the efficiency of management consulting from the viewpoint of expected results and goals of the organizations.

The applied purpose of the research is to present necessary suggestions regarding the hiring of a consultant and to increase the efficiency of management consulting services in businesses. It also 
deals with the issue on how the management consultants should respond to the managers' needs, act as a reliable and efficient adviser in public or private businesses and find their position in the Iranian market. Besides, other managers in all similar industries can apply the suggestions presented in this research.

\subsection{Theoretical framework}

\subsubsection{The concept of management consulting}

The experts in the field of management consulting have explained it in this way: When someone asks you an address and you tell him/her to get off at the next station, you have given a consulting service. Moreover, when you do not have direct control over people, but ask them to act based on your recommendations, you are faced with a complicated consulting problem.

Management consulting industry has turned into one of the lucrative fields in the service markets of the world in the 21 st century (Graubner, 2006). Porter believes that organizations unable to rethink, review and reconstruct are dead and this indicates the necessity of management consulting. With regard to the extent and variety of units and expertise, the managers, alone, are no longer able to be fully informed of all issues related to the organizations and to make decisions effectively and reasonably. The managers' power is reduced increasingly due to the complexity of the environment. In other words, a specialized duty is assigned to each unit and because of the limited expertise and time and increasing administrative duties, the managers cannot completely control all the units. Therefore, the senior manager is just one of the decision makers, not the only one. Therefore, the more technocrats are gaining power day by day, the more senior managers are losing their power. In fact, the main purpose of management consulting is to assist the managers and staff to develop their abilities in an environment full of self-confidence, understanding and organizational efficiency.

With regards to the stated definitions, it can be concluded that management consulting consists of helping the companies improve their performance through analysis of the existing situation and problems and designing the future plan. This help can be in the form of improving the current situation or transition to another situation. It can be done by identifying and describing successful experiences of the companies, analytical techniques, interpretation management, skills improvement, technology implementation, strategy codification or using the experts' opinions.

In brief, it can be added that a proper business consulting is beneficial in the following aspects:

- Logical, timely and correct decision making

- Obtaining accurate information

- Precise familiarity with the problems of the organization

- Implementing reasonable measures in the system

- Resolving the problems that may not be transmitted to the managers of the organization by the staff

- Accelerating the work

- Preventing the happenings that may damage the organization and the management

- Managing the time (proper control and dominance over the time)

- Correct identification of the management

- Presenting specialized suggestions regarding the management

- Appropriate use of human resources, financial resources and other resources

\subsubsection{Advantages of using consulting services}


- Independent view: Given that management consultants are not members of the organization, they can provide a clear picture of the problem and present new ideas and suggestions without bias. In other words, independent consultants' views help the organization find appropriate solutions to its problems without concern about possible criticisms of the beneficiaries.

- Special abilities: management consultants have knowledge, skill and expertise in a particular field and specialized area. Finding a person in the organization who is an expert in all areas is very difficult, if not impossible.

- Professional and periodical services: management consultants are able to provide professional services at any time determined by the company. The company incurs fewer costs by hiring consultants in comparison with hiring new managers and employees (especially in the long run).

\section{Key processes of consulting}

With increasing volume and complexity of the needs, traditional models of consultant-applicant relationship are no longer relevant and appropriate. It is the outcome of mutual dependence and diversity. Many factors are involved and new technologies and outsourcers play crucial roles, increasingly.

There are six basic elements in this systematic procedure as can be seen in Fig. 1. On the demand side, there are markets, which demand consulting, organizations which need consulting and consulting projects. On the supply side, there are the management consulting industry, consulting companies and individual consultants. These elements and their interactions have formed a new system called "business consulting ecosystem".

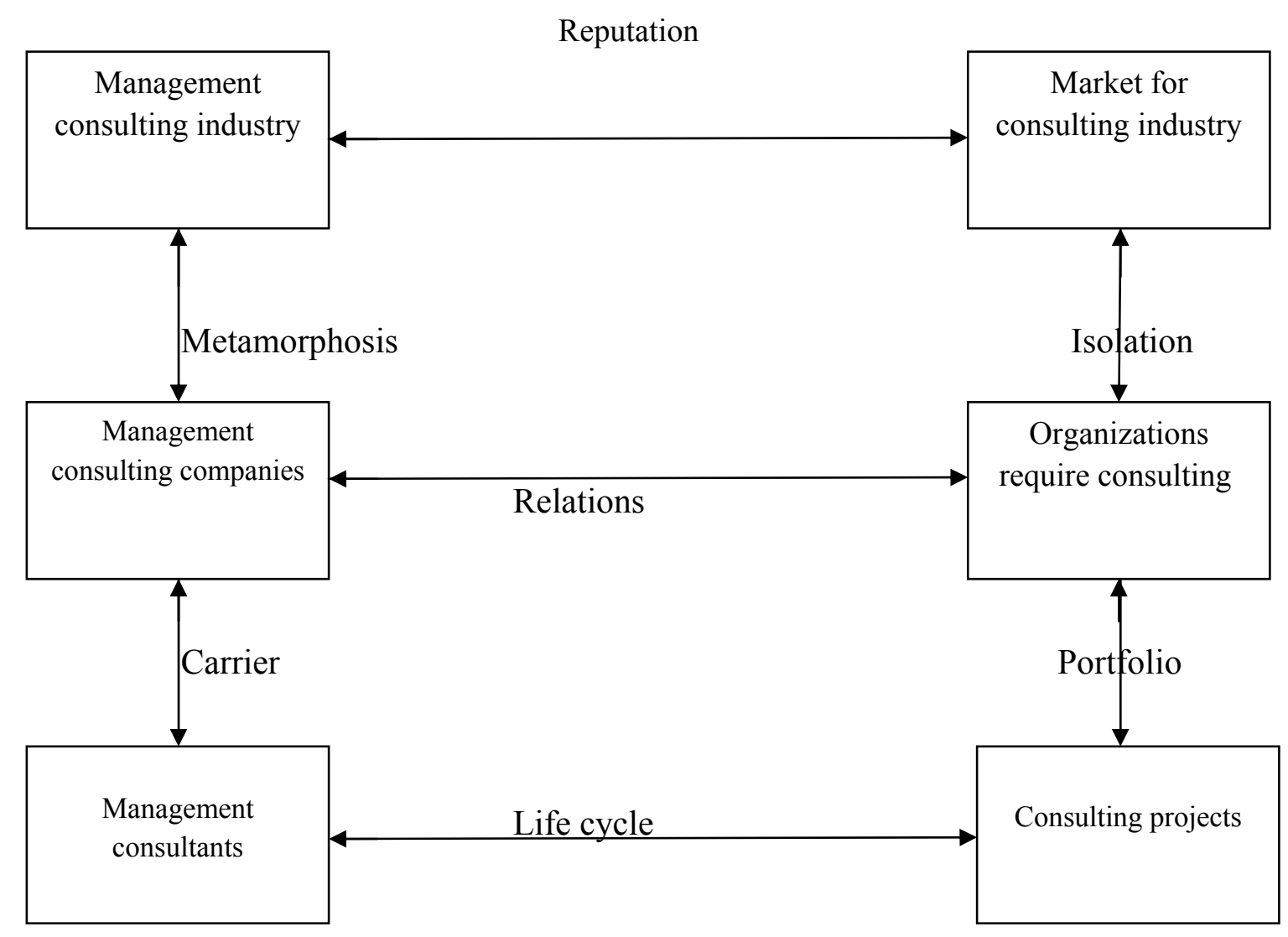

Fig. 1: Ecosystem of management consulting industry (Toppin \& Czerniawska, 2005) 
There are seven key relationships in this figure are defined as follows:

\subsection{Reputation}

Many consulting companies consider themselves to have no problems. Companies that are more reputable believe that their main distinctive feature is their valid brand. Smaller companies rely on their good customer relations and quality services to gain reputation. In fact, no organization can claim to have complete and inclusive reputation before its customers.

\subsection{Isolation}

Those who need consulting receive these services in an incomplete market, although they believe that they are responsible for their selection and use of consultants. They also believe that their responsibility is acceptable when they do not have adequate access to reliable data. All these issues are meaningful when the applicants have considerable awareness. The client systems rarely share their views on the management consultants' performance. It seems very strange in an environment in which consulting companies try to find solutions in the discussions related to applicants by publishing various books and papers.

\subsection{Metamorphosis}

Consulting is not a profession, because there is no ruling board to set and issue the standards and professional certificates for the verified consultants. Customers believe that in finding the consultants, they identify the qualifications, although competent consultants offer their services, voluntarily.

\subsection{Relationship}

Client systems are used to consider consulting projects as separate and comprehensive projects. However, this is changing due to three reasons,

- First time payment in exchange for specialized services has increased.

- Unlike the past, client systems benefit from various consultants in different areas.

- The new laws force the consultants to ensure that they will do their projects with a good customer relationship.

\subsection{Portfolio}

Complexities of the modern world result in that the customers (client systems) consider the project management consulting as a part of the portfolio of the company, not an isolated part. They should create balance between cheaper and more expensive projects and also between difficult, long-term projects and easier, short-term projects. An important part of the success of these organizations lies in the use of the external environment to achieve the internal order.

\subsection{Career}

Consulting should be called a job, although many consultants quit their job during the economic recession of 2009 and 2010. In comparison with other jobs, management consulting cannot be considered as a permanent, life-time job. However, proper consultation needs experienced and expert consultants, but how can it be determined? 


\subsection{Life cycle}

The clients spend a lot of time for preparation of working areas of the consultants during the consulting projects, but they do not cooperate on adaptation to change. Time, budget and quality standards are usually supplied from the beginning, but applying the changes during the project implementation is mostly ignored. It should be noted that leadership style, rules and methods of organizational thinking should be reviewed during the project life cycle more than anything else (Toppin \& Czerniawska, 2005).

\section{Key factors affecting the purpose of consulting and the efficiency of consulting services in businesses}

As can be seen in the main research model (Fig. 2), the key factors affecting the purpose of consulting, which influence the efficiency of consulting services include the following items,

3.1. Feedback: It refers to acquiring new information about oneself, others, group processes or the dynamic activities of the organization. The information associated with these issues have been ignored by the individual. It also refers to the activities and processes, which reflect an objective picture of the real-world applications. Awareness of these new details may lead to change if the feedback is not very threatening. Examining the feedback is very important in the business consulting programs.

3.2. Awareness of changing socio-cultural norms: When people be aware of the changes in the norms, which determine their behavior, they revise their behavior, attitudes and values. Awareness of the new norms and current destructive norms can be used as an incentive for change. When people recognize some differences between the results of the current norms and the optimal and desired results, it can lead to change.

3.3 The increase in the interaction and communications: Increasing the interaction and communications between individuals and groups may result in a change in attitudes and behaviors. For example, Humans claims that the increase in interaction leads to the increase in positive emotions and feeling. Individuals and groups that do not communicate very much suffer from a kind of autism and limited vision. Increase in communications reverses this situation and makes it possible for people to review their perceptions, attitudes and feelings. This mechanism is considered by all business consulting applications.

3.4. Encounter: The term refers to making clear and explaining the differences in feelings, beliefs, norms and attitudes to improve effective interaction. Encounter is a process which actively determines the real differences and works on them, constructively.

3.5 Training: This purpose refers to the activities designed to enhance and improve (a) knowledge and concepts (b) outdated views and beliefs and (c) skills. In any business consulting plans, training may be directed to several areas: performing the duties, social and human relations and behavior, organizational processes and dynamic activities and processes of management and leading the change. Training is a kind of change technique accepted for years.

3.6 Participation: It refers to activities, which increase the number of people involved in problem solving, goal setting and offering new ideas. Thus, participation is one of the main goals of business consulting, which increases the quality and acceptance of decisions, job satisfaction and employees' health and welfare. 
3.7 Increasing the responsibility: It is associated with activities, which make clear the individuals' responsibilities and the people responsible for supervising the performances.

3.8 Optimizing the systems: It refers to activities, which motivate people by providing the perspectives of the responsibilities and favorable horizon. Future must be valuable, desirable and achievable. Creation motivation among people and optimizing the systems are the results of different tasks such as providing the perspective of the future, public meetings, quality of work life, seminars on perspective, comprehensive quality programs and autonomous teams.

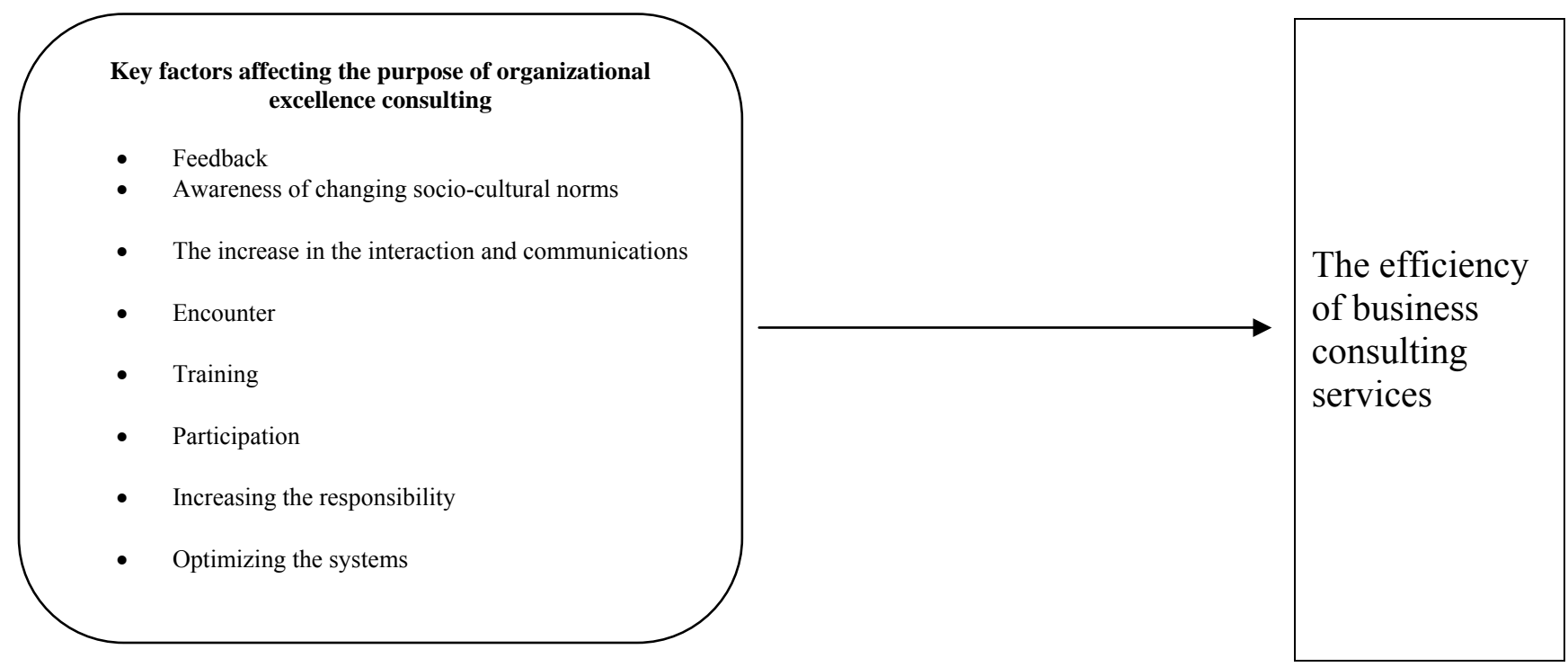

Fig. 2. The framework of the proposed study

\section{Research model}

\subsection{Research methodology}

This is a descriptive and survey research. In this study, the efficiency of business consulting services is considered as the dependent variables and key factors associated with the purpose of consulting are considered as the independent variables. The main research question is:

Do the key factors affecting each client system influence the efficiency of business consulting services?

\subsection{Primary research hypothesis}

The type of "purpose of consulting" influences the efficiency of business consulting services.

\subsection{Secondary research hypotheses}

Secondary research hypotheses, which are based on the variables extracted from the primary research hypothesis are as follows:

1. Providing feedback to the client system influences the business consulting services. 2. Awareness of the changing socio-cultural norms in the client system influences the business consulting services. 
3. The increase of interactions and communications in the client system influences the business consulting services.

4. Explaining the differences and encounter in the client system influences the business consulting services.

5. Training the staff of the client system influences the business consulting services.

6. Management of the employees' participation in the client system influences the business consulting services.

7. The increase in responsibility of the client system influences the business consulting services.

8. Optimizing the existing mechanisms of the client system influences the business consulting services.

\subsection{Data collection}

The primary source is a questionnaire and the secondary sources include books, theses, papers, internet, etc.

\subsection{Statistical population and number of samples}

Statistical population includes the managers of small and medium-sized enterprises (SME) associated with food industries in Tehran province. The number of samples using statistical formulas is 90 .

\subsection{Sampling method}

Sampling method is simple random sampling selected from the given population. The samples are extracted from the statistical diskette of the Ministry of Industries and Mines.

\subsection{Data analysis}

Formal test will be used to determine the validity of the questionnaire. Cronbach alpha will be used to determine the reliability of the questionnaire. Other statistical tests will also be used including the Pearson's test for testing the interval variables and Chi Square test for identifying ranking variables. The data will be analyzed using the relevant software such as SPSS. To measure the influence of independent variables on dependent variables, multiple linear regression will be utilized.

\section{Research findings}

Out of the 90 questionnaires collected, 28 cases (31.1 percent of the total number of respondents) belonged to female and 56 cases (62.2 percent of the total number of respondents) belonged to male respondents. Approximately 13.3 percent of the respondents were 25 to 35 . Other age groups included: 34.4 percent 35 to $45,24.5$ percent 45 to 55 and 17.8 percent 55 or older. Meanwhile, 10 percent of the respondents did not mention their age. According to data obtained from the questionnaires, about 3.3 percent of the respondents had high school diploma or they had not finished high school. Based on the education level, other people were categorized into these groups: 15.6 percent had associate degree, 40 percent had BA and 31.1 percent of the respondents had postgraduate degree.

\subsection{Primary research hypothesis: The purpose of consulting influences the efficiency of business consulting services.}

Evaluation of this hypothesis using the empirical evidences of the above table and the Pearson's test indicates that, according to the Pearson's coefficient, there is a positive relationship with the value of 0.56 between the two variables including the purpose of consulting and the efficiency of business consulting services and its intensity is moderate. On the other hand because the significant level of 
sig: 0.00 is less than $\alpha=0.01$, the hypothesis that states there is no relationship between these two variables will be rejected with the confidence level of 99 percent. The hypothesis based on the relationship between these two variables will be verified with 99 percent confidence. Therefore, the two variables including the purpose of consulting and the efficiency of business consulting services are related.

\section{- Hypothesis 1: Providing feedback to the client system influences the efficiency of business consulting services.}

Evaluation of this hypothesis using the empirical evidences of the above table and the Chi test indicates that given the significance level of sig: 0.007 which is less than $\alpha=0.01$, the hypothesis that states there is no relationship between these two variables will be rejected and the hypothesis based on the relationship between two variables will be confirmed. Therefore, these two variables including providing feedback to the client system and the efficiency of business consulting services are related.

\section{- Hypothesis 2: Awareness of the changing socio-cultural norms in the client system influences the business consulting services.}

Evaluation of this hypothesis using the empirical evidences of the above table and the Pearson's test indicates that, according to the Pearson's coefficient, there is a moderate and positive relationship with the value of 0.41 between two variables of awareness of changing socio-cultural norms in the client system and the efficiency of business consulting services. On the other hand, according to the significant level of sig: 0.000 which is less than $\alpha=0.01$, the hypothesis that states there is no relationship between these two variables will be rejected and the hypothesis based on the relationship between two variables will be verified. Therefore, two variables of awareness of changing sociocultural norms in client system and the efficiency of business consulting services are related.

\section{- Hypothesis 3: The increase of interactions and communications in the client system influences the business consulting services.}

Evaluation of this hypothesis using the empirical evidences of the above table and the Pearson's test indicates that according to the Pearson's coefficient there is a moderate and positive relationship with the value of 0.91 between two variables of the increase of interactions and communications in client system and the efficiency of business consulting services. On the other hand, according to the significant level of sig: 0.000 which is less than $\alpha=0.01$, the hypothesis that states there is no relationship between these two variables will be rejected and the hypothesis based on the relationship between these two variables will be verified. Therefore, two variables of the increase of the interactions and communications in the client system and the efficiency of business consulting services are related.

- Hypothesis 4: Explaining the differences and encounter in the client system influences the efficiency of business consulting services.

Evaluation of this hypothesis using the empirical evidences of the above table and the Chi square test indicates that because the significant level of sig: 0.002 is less than $\alpha=0.01$, the hypothesis that states there is no relationship between these two variables will be rejected and the hypothesis based on the relationship between these two variables will be verified. Therefore, two variables of the differences and encounter in the client system and the efficiency of business consulting services are related.

- Hypothesis 5: Training the staff of the client system influences the business consulting services. 
Evaluation of this hypothesis using the empirical evidences of the above table and the Pearson's test indicates that according to the Pearson's coefficient there is an intense and positive relationship with the value of 0.53 between two variables of training the staff and the efficiency of business consulting services. Therefore, according to the significant level of sig: 0.000 which is less than $\alpha=0.01$, the hypothesis that states there is no relationship between these two variables will be rejected with 99 percent confidence and the hypothesis based on the relationship between these two variables will be verified with 99 percent confidence. Therefore, two variables of training the staff and the efficiency of business consulting services are related.

- Hypothesis 6: Management of the employees' participation in the client system influences the efficiency of the business consulting services.

Evaluation of this hypothesis using the empirical evidences of the above table and the Pearson's test indicates that according to the Pearson's coefficient there is a moderate and positive relationship with the value of 0.39 between two variables of the management of the employees' participation and the efficiency of business consulting services. On the other hand, according to the significant level of sig: 0.001 which is less than $\alpha=0.01$, the hypothesis, which states there is no relationship between these two variables will be rejected with 99 percent confidence and the hypothesis based on the relationship between these two variables will be verified with 99 percent confidence. Therefore, two variables of management of the employees' participation and the efficiency of business consulting services are related.

- Hypothesis 7: The increase in responsibility of the client system influences the business consulting services.

Evaluation of this hypothesis using the empirical evidences of the above table and the Chi test indicates that according to the significant level of sig: 0.000 which is less than $\alpha=0.01$, the hypothesis that states there is no relationship between these two variables will be rejected and the hypothesis based on the relationship between these two variables will be verified. Therefore, two variables of the increase in responsibility of the client system and the efficiency of business consulting services are related.

- Hypothesis 8: Optimizing the existing mechanisms of the client system influences the business consulting services

Evaluation of this hypothesis using the empirical evidences of the above table and the Pearson's test indicates that according to the Pearson's coefficient there is a moderate and positive relationship with the value of 0.38 between two variables of optimizing the existing mechanisms in client system and the efficiency of business consulting services. According to the significant level of sig: 0.000 , which is less than $\alpha=0.01$, the hypothesis that state there is no relationship between these two variables will be rejected with 99 percent confidence and the hypothesis based on the relationship between these two variables will be verified with 99 percent confidence. Therefore, two variables of optimizing the existing mechanisms in the client system and the efficiency of business consulting services are related.

\section{Table 1}

Summary of the multiple regression model (primary research hypothesis) regarding the efficiency of business consulting services

\begin{tabular}{|c|c|c|c|c|c|}
\hline \multirow[b]{2}{*}{ Variable } & \multicolumn{4}{|c|}{ B(standard impact factor) } & \multirow[b]{2}{*}{$\mathrm{F}$} \\
\hline & Reputation & Formal aspect of the contract & $\mathrm{R}$ & $\mathrm{R}^{2}$ & \\
\hline beta coefficient & -0.27 & 0.17 & 0.43 & 0.19 & 4.85 \\
\hline Significant level & 0.049 & 0.16 & & & \\
\hline
\end{tabular}


In this study, for measuring multiple-variable regression a combined method (Enter) is used. In this method, all independent variables enter the analysis simultaneously and the effects of all independent variables on the dependent variable will be studied. Linear regression analysis indicates the impact of independent variables, reputation, formal aspect of the contract, providing a specific perspective, expertise, intervention technique, modeling and ethical characteristics on the efficiency of business consulting services.

Table 1 shows that multiple correlation coefficient $(\mathrm{R})$ equals to 0.43 . It means that the above independent variables have simultaneously related to the efficiency of business consulting services with the value of 43 percent. Coefficient of determination (R2) equals to 0.19 , which means that 19 percent of the changes in the efficiency of business consulting services is explained by the above variables. In the same table, the value of (F) equals to 4.85, which means that one of these independent variables has a significant coefficient in the regression equation.

Table 1 shows that the variables of providing a specific perspective, intervention technique and modeling have been removed from the model due to lack of significance. Four variables of reputation, formal aspect of the contract, expertise and ethical characteristics have been significantly related to the efficiency of business consulting services. Ethical characteristics variable, with the value of 35 percent, has the most significant relationship with the efficiency of business consulting services.

\section{Conclusion}

It should be noted that at present, there are about 7370 production units working in the food industries of Iran and most of these industries are located in Tehran. Since about 90 percent of the Iranian production units are considered as SME, it can be concluded that most of the production units active in food industries are also SME. These units, annually, produce about 25 million tons of agricultural products in Iran and send them to the market. Food industries produce one third of the total production of the country and in this respect are placed in the second rank after heavy industries. This indicates the high importance of this industry in developing domestic production and shows the significant position of this sector among the industries of the country.

According to the results and findings of this study, all selected food enterprises based in Tehran regard eight major independent variables of the study to be important in selecting and increasing the efficiency of their business consulting. This shows the intelligent selection of the primary model and conceptual framework of the research. In this conceptual framework, the researchers have tried to exactly and comprehensively review all dimensions and angles of management consulting services in Iranian businesses. New studies in this area have been reviewed. Therefore, the present study can be considered as a pioneer in the field.

As can be seen in the primary research model, eight factors including providing feedback to the client system, awareness of the changing socio-cultural norms, the increase in interactions and communications of the client system, the applicant, explaining the differences and encounter in the client system, training the staff of each client system, management of the employees' participation in the client system, increasing the responsibility of the client system and optimizing the mechanisms in the client system were examined. The model of research findings shows that the purpose of consulting influences the efficiency of business consulting services.

Based on the research findings, the hypothesis that stated providing feedback to the client system influenced the efficiency of business consulting services was confirmed. In fact, the findings confirm that small and medium-sized food enterprises in Tehran consider the amount of feedback from 
implemented methods and programs to the organizational consultant as one of their main reasons in selecting their management consultant. Based on the model of research findings, this hypothesis that stated awareness of changing socio-cultural norms in the client system influenced the efficiency of business consulting services was confirmed. Thus, small and medium-sized food enterprises in Tehran consider the awareness of changing socio-cultural norms in their organization as one of the factors influencing the efficiency of business consulting services. In fact, it can be claimed that according to our research, consultant's awareness of the new norms and their desired results, as well as his/her awareness of the current destructive norms of the organization and providing the personnel with the differences between current norms and desired results influence the efficiency of business consulting services.

A part of the model of research findings is related to the influence of the variable of increasing the interactions and communications of the client system on the efficiency of business consulting services. This means that increasing the interactions and communications of the client system influences the efficiency of business consulting services. Thus, it can be argued that small and medium-sized food enterprises in Tehran pay attention to increasing the interactions and communications of their client system when they select their management consultant.

Our research findings indicate that increasing the interaction and communications between individuals and groups in the organizations, on one hand, and the consultant's constructive communication and interaction with the staff of the client organization, on the other hand, influence the efficiency of management consulting services. Presence of people who exchange their feelings through constructive dialogues can create positive and long-term relations based on the friendship and affection among the managers, staff and consultants of the organization.

In this study, identifying and removing the barriers to development and learning in the organization were questioned as the measuring index of this variable. Based on the results of testing the seventeenth research hypothesis, this hypothesis was confirmed. It means that the differences and encounter in the client system influence the efficiency of business consulting services.

The findings indicate that training the staff and the efficiency of business consulting services are significantly related. Small and medium-sized food enterprises in Tehran agree that training the staff by the consultant about how to do organizational duties, establish social-human relations and carry out organizational processes highly influences the efficiency of business consulting services. The managers of these companies have positive views regarding the effect of explaining and informing about the change programs by the consultant on the efficiency of business consulting services. Based on the results of this study, management of the employees' participation influences the efficiency of business consulting services.

In order for organizational consultants to show their commitment to professional ethics and to develop it in their organization, they should provide the staff with the required information and give them the opportunity to participate in the affairs.

Our research findings indicate that if the business consultants want to be successful, at the beginning they should identify those responsible for implementing the results of work and after receiving their comments about difficulties in implementing the change, involve them in the process as far as possible and help them learn how to cope with the new system.

It should be added that in our findings, participation refers to activities, which add the number of people involved in problem solving, goal setting and providing new ideas for cooperation. Thus, participation is one of the main goals of business consulting that increases the quality and acceptance of decisions, job satisfaction and employee's health level and welfare. 
Our research findings indicate that increasing the responsibility in the client system, as one of the important goals of consulting, influences the efficiency of business consulting services. The findings of this study show that managers of small and medium-sized food enterprises in Tehran agree that management consulting services are more efficient when the consultant, without having direct responsibility, plays the role of a guide or facilitator and in this way increases the responsibility in the client system.

Our research findings show that optimizing the mechanisms in the client system influences the efficiency of business consulting services. Type and intensity of this effect, according to the Pearson's correlation coefficient, is assessed to be 0.38 , average and positive.

The findings indicate that managers of small and medium-sized food enterprises in Tehran believe that providing accurate details of the quality of consulting programs, presenting a clear picture of the horizons faced by the organization and holding thank you ceremonies are among the mechanisms affecting the efficiency of management consulting services.

\section{Acknowledgment}

The authors would like to thank the anonymous referees for their comments on earlier version of this work.

\section{References}

Biswas, S., \& Twitchell, D. (1999). Management Consulting: A Complete guide to the Industry. New York: Wiley and Sons.

Block, P. (2000). Flawless consulting (2 $2^{\text {nd }}$ ed.). San Francisco: Jossey-Bass/Pfeiffer.

Bechina A. A., \& Bommen T. (2006). Knowledge sharing practice: Analysis of global Scandinavian consulting company. Electronic Journal of Knowledge Management, 4(2), 109- 116.

Beer, M. \& Nohria, N. (2000). Cracking the code of change. Harvard Business Review, 78(3), 131141.

Cardon M. \& Steven C. (2004). Managing human resource in small Organization: what do we know. Human Resource Management Review, 14, 295-323.

Cadman, B., Ellen Carter, M., \& Hillegeist, S. (2010). The incentives of compensation consultants and CEO pay. Journal of Accounting and Economics, 49(3), 263-280.

Cummings, W. (2001) Essentials of Organization Development and Change. $7^{\text {th }}$ ed. South Western, 56-65.

Chnang, H. J. (2002). The characteristics and internationalization of Taiwan consulting business, Master 's Thesis, National Taiwan University.

Christian K. (2002). The emergence of second generation knowledge management in engineering consulting. International Council for R \& D in Building, and construction Conference.

Deelmann, T., \& Mohe, M. (2006). Selection and Evaluation of Consultants. 1 , Rainer Hampp Verlag.

Graubner, M. (2006). Task, firm Size, and Organizational Structure in Management Consulting: An Empirical Analysis from a Contingency Perspective, Dissertation European Business School Oestrich-Winkel .

Homburg, C., \& Stebel, P. (2009). Determinants of contract terms for professional services. Management Accounting Research, 20(2), 129-145.

Richter, A., \& Niewiem, S. (2009). Knowledge transfer across permeable boundaries: An empirical study of clients' decisions to involve management consultants. Scandinavian Journal of Management, 25(3), 275-288. 
Sturdy, A., Werr, A., \& Buono, A. F. (2009). The Client in Management Consultancy. Research Mapping the territory. Scandinavian Journal of Management, 25(3), 247-252.

Toppin, G., \& Czerniawska, F. (2005). Business Consulting, Profile Books Ltd. The Economist Newspaper Ltd, London.

Tsai, C.H., Chang, C.L., \& Chen, L. (2006). A Case Study of Knowledge management (formation consulting company International). Journal of the Computer, the Internet and Management, 14(3), 60-78.

Vinas, B.C.B., Bessant, J., \& Pe'rez, G.H. ( 2001 ). A conceptual Model for the development of Technological Management Process in manufacturing companies in developing countries. Technovation, 21, 345-352. 